\title{
Caitro Soto: "De canto, baile y cadenas". Testimonio y cultura Afroperuana
}

\author{
Milagros Carazas \\ Universidad Nacional Mayor de San Marcos \\ milagroscarazas@yahoo.com
}

\section{Resumen}

Analiza la obra De cajón Caitro Soto. El duende de la música afroperuana (1995), un libro dedicado al artista Carlos Soto de la Colina (1934-2004). Indaga su historia de vida, la tradición oral, los géneros musicales afroperuanos. Reflexiona sobre la canción afroperuana y su contenido.

Palabras clave: Comunidad afroperuana, Testimonio, Identidad, Música afroperuana, Canción

\section{Abstract}

Analyze the work De cajón Caitro Soto. El duende de la música afroperuana (1995), a book dedicated to the artist Carlos Soto de la Colina (1934-2004). It explores its history of life, oral tradition, the musical genres Afro-Peruvian. Reflect on the song Peruvian and its content.

Keywords: Afro-Peruvian Community, Testimony, Identity, Afro-Peruvian Music, Song 


\section{Caitro Soto: "De canto, baile y cadenas". Testimonio y cultura Afroperuana}

De cajón Caitro Soto. El duende de la música afroperuana (1995), es un libro que viene acompañado de un CD conmemorativo, como un homenaje de la Telefónica del Perú al connotado artista Carlos Soto de la Colina (1934-2004). En buena cuenta se enlaza felizmente la literatura y la música. El texto contiene no sólo el testimonio de Caitro Soto, sino que aparecen varios trabajos de otros autores (como Luis Miguel Glave, José Durand y Nicomedes Santa Cruz), a manera de rescate y para complementar el volumen.

Pero, sin duda, el foco de interés es lo concerniente al texto de Caitro Soto, en el que se distingue dos secciones. La primera ha sido denominada "Yo recuerdo", y abarca varias páginas en las cuales el conocido músico relata algunos pasajes de su vida. En cambio, la segunda sección se llama "Una historia de cada canción”. Como se indica, se presenta las canciones al mismo tiempo que Caitro Soto explica el origen de estas o narra alguna anécdota alrededor de ellas. Ambas secciones están acompañadas de muchísimas fotos, tanto del músico como de la costa sur del país (sobre todo, de Chincha y Cañete).

Ahora bien, mi artículo busca una primera aproximación a estas dos secciones. Por un lado, pretendo llevar a cabo una lectura interpretativa del testimonio de Caitro Soto, en el que se combinan sabiamente la historia de vida, la música negra y la tradición oral afroperuana. Y, por otro lado, se trata de analizar los géneros musicales y literarios afroperuanos a los que se alude en este libro.

Me importa reflexionar sobre la canción afroperuana y su contenido. Esta no es una tarea fácil, ya que se trata de un tema fronterizo entre la literatura, la antropología y la musicología, muy poco explorado en nuestro medio. Al igual que Robert Hodge (1999), entiendo la canción como una forma de expresión oral de compleja naturaleza, cuyo análisis debiera explicar qué clase de contenidos transmite y de qué manera lo hace. 
Así, ¿qué temas expresa el sujeto afroperuano en sus canciones y cuál es su significado? ¿Cómo se plantea el pasado de esclavitud y la diáspora en la canción y en el testimonio? ¿Cómo se construye la identidad cultural y la representación del sujeto afroperuano en el discurso de Caitro Soto? Estas son algunas de las interrogantes que son de mi interés, que espero responder en el presente trabajo de carácter ecléctico y plural.

\section{Carlos Soto de la Colina: un acopio de recuerdos}

Como ya se adelantó, la sección "Yo recuerdo" está referida a la historia de vida de Caitro Soto. Está conformada por diez subdivisiones, cada una lleva un título que resume de alguna manera el contenido de este, a saber: "En San Luis de Cañete"; "La Navidad y la danza de los negritos"; "Hincado ante el Señor de los Milagros"; "Entre lonas, costales y volantes"; "Nadie quiere negro con pena"; "Zapateando"; "Con 'Pancho Fierro' al Municipal"; "Cajoneadores y cajoneros"; "Chabuca Granda, mi madre"; y "De tal palo..."

Ahora bien, atendiendo a la lectura rigurosa de cada subdivisión, se puede observar que algunos hechos están localizados en San Luis de Cañete y remiten al pasado, a la etapa de niñez y la vida campesina; mientras que otros acontecimientos suceden en Lima y el extranjero, con más precisión coinciden con la etapa juvenil y la etapa adulta, en la que Caitro Soto se desempeña en varios oficios hasta consagrarse como músico cajonero al lado de Chabuca Granda, y luego se centra en la etapa de la vejez en la que finalmente organiza su propio grupo.

Como toda historia de vida esta no se presenta de manera lineal, está sujeta al vaivén de los recuerdos y la intervención de la memoria. Esta selecciona o busca en la mente hechos o episodios, unos más trascendentales, vívidos y, o traumáticos que otros. Como explica Hermann Parret (2008), el recuerdo deja una traza o, mejor dicho, una especie de huella o escritura en el individuo. Este adquiere sentido y una valoración; es compartido por medio del lenguaje.

En este caso, se trata del testimonio de Caitro Soto, aunque no muy extenso, eso sí, enriquecido por la historia de San Luis de Cañete, la mención de festividades (como la Navidad, la danza de negritos, el carnaval), la religiosidad (la procesión del Señor de los Milagros), las danzas y formas musicales (el panalivio, ${ }^{1}$ el huanchi-

1 Es un canto de lamento de los esclavos para expresar sus penas por la esclavitud. El más difundido es "La Molina" del cantor y guitarrista Francisco Ballesteros Nole (1888-1984) y Samuel Márquez (1892- ), cuya letra dice: "A la Molina no voy má / poque chan / azote sin cesa". Fue recogido por Nicomedes Santa Cruz en su disco Socabón. Sobre el panalivio, revisar N. Santa Cruz (1964b), Acosta Ojeda (2009a) y Tompkins (2011). 
hualito, ${ }^{2}$ la zamacueca ${ }^{3}$, el festejo, etc.), las manifestaciones culturales (el zapateo, el toque de cajón), las formas poéticas (la décima), el lenguaje (los afronegrismos y los vocablos populares), las costumbres y las creencias locales, etc.

Es de mi opinión, una lectura atenta del testimonio de Caitro Soto da como resultado la recurrencia de tres temas específicos, a saber: 1) la historia personal y familiar mezclada con la historia local de San Luis de Cañete, en especial el correspondiente al período de la hacienda y la vida rural; 2) la presencia de los elementos culturales y musicales que reafirman una identidad, y que se remiten al pasado de esclavitud; y 3) los episodios de la carrera artística del informante en Lima y el extranjero. Me voy a detener en cada uno de ellos con más detalle.

En primer lugar, Caitro Soto recuerda varios hechos que suceden en San Luis de Cañete y sus alrededores, entre 1934 y 1948, que coinciden con la etapa de niñez y la vida rural. Son años difíciles cuando ocurre la muerte del padre, la deserción escolar, el ingreso a la vida laboral y la pobreza. Esto se puede apreciar en la siguiente cita:

Crecí en un hogar humilde con mis siete hermanos, José Luis, Ronaldo, Orlando, Enrique, Elia, Gilda y Rori [...] De niños éramos felices. Si bien éramos pobres y no teníamos padre, todos los hermanos éramos muy unidos. Trabajábamos en las vacaciones de colegio sembrando arroz, abonando las plantas, pañando algodón, desgranando [...] Yo me pegaba mucho a mi madre porque mi padre había muerto cuando tenía siete años. A mí me gustaba el trabajo y la acompañaba al campo para ayudarla. Íbamos a las haciendas Montalbán, Arana y Casablanca. (p. 41).

A pesar de lo anterior, el informante idealiza el pasado, lo rememora con cierto sentimiento positivo, es decir este es un período de su vida que además se valora por la unión familiar, la alegría de la música negra y la satisfacción del trabajo remunerado. Es de este modo que:

Cuando trabajaba en las haciendas sembrábamos el arroz cantando, porque teníamos la idea que el tiempo así se pasaba más rápido. Entrábamos a las siete y media de la mañana y terminábamos hacia las cuatro o cinco, cuando pasaba el avión del correo. Ese era el reloj, con eso nos guiábamos. Para ir a la hacienda nos transportábamos en burro, o bien a pie o a veces en un camión que contrataban para llevar

2 Es una canción en cuartetas para la Yunza o festividad agraria en Chincha, en época de carnaval. Aún tiene vigencia. Algunas canciones han sido recopiladas por Chalena Vásquez, los Hermanos Ballumbrosio, Octavio Santa Cruz y Susana Baca, entre otros.

3 Fue una danza que tuvo mucha acogida en Perú (se bailaba en la Pampa de Amancaes), Bolivia, Argentina y Chile en el siglo XIX. Es anterior y da paso a la Marinera. Según Victoria Santa Cruz (1974: p. 55), es una danza recreada que se bailó por vez primera en la Plaza de Acho en 1968, y que era parte del repertorio del grupo Teatro y danzas negros del Perú. Se tomó como modelo el vestuario que aparece en las acuarelas de Pancho Fierro. La versión musical aparece en su disco Ritmos y aires afroperuanos. Hoy en día existen algunas zamacuecas creadas especialmente para el espectáculo, pero no es una práctica popular. Ha sido motivo de estudio por parte de Romero (1939), Acosta Ojeda (2009d) y Tompkins (2011). 
el abono. Pero esto se daba muy rara vez pues, generalmente, íbamos caminando y tardábamos una hora, una hora y media, según la hacienda. (p. 42).

Efectivamente, como explica Parret (2008), en todo ejercicio de la memoria se da una búsqueda y una afección. Es decir, cuando el enunciador busca y selecciona recuerdos en su mente, al mismo tiempo provoca en él sentimientos y afecciones. La imagen del pasado es valorada. Su presencia establece una relación que modaliza tanto lo sensible (afecta los sentidos) como lo afectivo (despierta sentimientos positivos o negativos).

Asimismo, es interesante observar el contraste entre el campo y la ciudad. La experiencia personal de Caitro Soto es que "la vida es linda en la chacra" (p. 42) o, mejor aún, "en el campo, en el fondo, el que se muere de hambre es porque quiere: todo es cuestión de ingeniárselas" (p. 42). Más adelante, veremos que la ciudad es sinónimo de migración forzada, nostalgia familiar y trabajo arduo. Lo que establece obviamente dos espacios, uno del cual se parte (Cañete) y otro al cual se llega (Lima), que bien se resume en el allá y el aquí. Como sostiene Antonio Cornejo Polar (1996), el discurso del migrante es descentrado ya que se construye alrededor de varios ejes. Entiéndase bien, el desplazamiento migratorio duplica el territorio del sujeto.

En segundo lugar, el testimonio que nos alcanza Caitro Soto evidencia una diversidad de manifestaciones musicales y danzantes, así como la riqueza de los diferentes elementos de la cultura afroperuana, más concretamente la de San Luis de Cañete. Caitro Soto revela que desde temprana edad estuvo relacionado con la música y el baile. En 1941, "A los siete, ocho años ya tocaba la sonaja de chapa chancada y hacía zapateo" (p. 44) y, en el año de 1946, a "los doce años, era integrante de la banda de la localidad: Yo tocaba bombo, redoblante y platillos" (p. 45).

Es importante observar el valor que logra la tradición culinaria y musical de la familia, así como la herencia cultural adquirida por el informante desde la niñez. Como Caitro Soto explica, "cuando mi mamá regresaba del campo cosía hasta tarde. Los días de fiesta preparaba anticuchos y picarones. Ella y mi abuela tenían muy buena mano para cocinar. Hacían dulces y manjares” (pp. 41-42). Pero todavía es más aleccionador cuando él se refiere a la música negra:

Una de ellas era "Congorito" que, creo es palabra africana, del Congo. Festejo era lo que más se bailaba y los lamentos "La Molina" y "El Payandé" 5 [...] En mi casa,

$4 \mathrm{Su}$ autor es el pianista Filomeno Ormeño quien la compuso a partir de un fragmento. Existe una versión del festejo "Congorico", recopilada por Manuel Quintana Flores "El Canario Negro" (1880-1959) y cantada por Alicia Maguiña, que fue grabada en 1969.

5 "El Payandé", llamada también habanera, evoca la esclavitud. Tiene dos autores, el colombiano Vicente Holguín (letra) y Luis Eugenio Albertini (música). Aparece en el Cancionero popular de 1892. Una versión de "El Payandé" fue recogida previamente por Eduardo Montes y César Augusto Manrique en sus grabaciones de 1911. Fue cantada por Eloísa Ángulo y grabada en disco Odeón por Ima Súmac. El Grupo Perú Negro grabó también una versión, la voz es de Lucila Campos. 
mi madre Benedicta y su hermana cantaban, bailaban. A veces se reunían donde algún familiar [...] toda esa gente era folclorista [...] allí se hacían espectáculos de todo tipo pero con números de música negra; más había de varietés y se escuchaba vals, polca, mazurca [...] Mi madre, mi gorda linda, era una mujer alegre. A mí me viene la música por ella y por mi tía, la mamá de mi hermano Ronaldo Campos. Ellos nos enseñaban. (p. 45).

No cabe duda de que es impresionante el conocimiento que evidencia Caitro Soto sobre los géneros musicales y literarios afroperuanos. En su testimonio se alude, por ejemplo, al panalivio, el festejo, la danza de negritos, el huanchichualito, el alcatraz, el landó, el aguanieve, ${ }^{6}$ los pregones, ${ }^{7}$ la décima, etc. Su bagaje cultural y artístico es amplio. Interesa destacar que todo ello contribuye a la reafirmación de la identidad cultural del informante, así como su relación con un pasado histórico heredado.

Como dice el propio Caitro Soto: "A veces [los negros] se acordaban de sus ancestros y se sentían tristes y deprimidos. Ya no eran esclavos pero se acordaban de sus padres. Hay algunas cosas que desconozco, pero esto me lo contaba mi abuela materna cuya madre fue esclava" (p. 49). En el siguiente apartado volveremos a esta temática. Basta con lo dicho hasta aquí.

Vale la pena observar lo siguiente. Cuando aludo a la identidad cultural lo hago en el mismo sentido que Stuart Hall (2010, p. 351). Es decir, considero que la identidad cultural es también "un asunto de 'llegar a ser' así como de 'ser"; está en constante transformación. Al mismo tiempo se encuentra sujeta en el juego continuo de la cultura, la historia y el poder. De esta manera, importa la forma en que el sujeto está posicionado y en su interior cómo se posiciona, por medio de las narrativas del pasado.

Por otro lado, falta contemplar dos tópicos más: el cajón ${ }^{8}$ y el zapateo. Como es sabido, Caitro Soto poseía un dominio virtuoso sobre el toque de cajón y el baile del zapateo. En cuanto al primero, él considera que el cajón como instrumento es

6 Es un baile de zapateo para solista o en contrapunto, mayormente entre danzantes masculinos, muy difundido en la provincia de Chancay. Es acompañado de guitarra. Se diferencia del zapateo por la técnica empleada, en el que se baila sobre la punta de los pies y se realiza figuras como el escobillado, por eso es considerado como un juego de habilidad. Nicomedes Santa Cruz grabó una versión de la melodía, interpretada por Vicente Vásquez, en su disco Cumanana en 1975. Más información en Durand Allison (1999) y Tompkins (2011).

7 Es un canto usado para la venta de productos. La pianista y compositora criolla Rosa Mercedes Ayarza transcribió, presentó y publicó un conjunto de canciones, entre ellas pregones, en la década de los cuarenta. Es sabido que Ayarza recopiló y grabó muchas de estas canciones de los hermanos Elías y Augusto Ázcuez Villanueva, sin recibir ellos ningún reconocimiento. Con el paso de los años, Victoria Santa Cruz, junto con su hermano Nicomedes, interpretó numerosos pregones en sus presentaciones. Estos han sido recogidos en su disco Ritmos y aires afroperuanos. En 2006, con el auspicio de Edelnor y Endesa, se publicó el libro Lima y sus pregones, que viene acompañado con un CD y un DVD.

8 Sobre el estudio del cajón, revisar Rafael Santa Cruz (2006), Denegri (2009), Tompkins (2011), Rocca (2012) y Vallejos (2012). 
de origen peruano y su antecedente inmediato es el tambor africano, el cual era también un medio de comunicación. En el caso del Perú, "el amo le quita el tambor, ahí nace el cajón” (p. 54). Lo que demostraría la sapiencia del afrodescendiente para reemplazar y construir creativamente este singular instrumento, y superar el despojo cultural y musical del cual fue objeto alguna vez.

Interesa agregar que Caitro Soto distingue entre el cajoneador y el cajonero. E1 primero sería aquel que golpea fuerte sin "respetar al cantante y a los músicos acompañantes" (p. 54); en cambio, el segundo toca armoniosamente el instrumento e inventa nuevos golpes. Es obvio que la maestría del cajón está destinada a unos pocos, a ellos se les denomina con razón cajoneros, que bien sería sinónimo de "creador".

En cuanto al zapateo, en especial en la Danza de negritos de Chincha, está definido por Chalena Vásquez (1982, p. 78) como un "instrumento de percusión, dada la importancia que tiene dentro del fenómeno sonoro", cuyos pasos básicos o "pasadas” se combinan siguiendo el compás de un violín. Según cuenta Caitro Soto, se puede distinguir hasta tres tipos: 1) el zapateo de chacra, descalzo, con pie plano y sobre la tierra, que solía hacerse en las haciendas; 2) el zapateo con zapato en la iglesia para la Navidad y la danza de los negritos, acompañado por el violín macho; y 3) el zapateo para el espectáculo, realizado en el teatro, en el que se prefiere la "punta y el taco, con redobles que no usan todo el pie" (p. 50).

En cualquier caso, el zapateo es sobre todo una competencia y por tanto adquiere mayor sentido en el contrapunto entre bailarines. Como bien explica Caitro Soto: "Siempre hay un rival y uno tiene que superar [...] En su turno el zapateador es libre y siempre zapatea en contrapunto. Cada uno hace su figura, uno por uno, y siempre tiene que hacerla mejor que el anterior. $\mathrm{El}$ zapateo tiene sus amarres. Como comienza, así tiene que terminar" (p. 50).

Me parece necesario puntualizar que el informante recuerda además dos décimas populares: "Apuesto hasta mi pellejo a la pata de mi tío" y "Anoche jugué y perdí, lo mismo será mañana”. Respecto a la primera, Soto apenas menciona el primer verso; pero, se sabe que una versión completa ha sido recopilada: 1) en Erasmo. Yanacón del valle de Chancay (1974), en el que la glosa va como sigue: "Apuesto hasta mi pellejo / a las patas de mi tío, / zapateador más completo / desde Boza a Chancayllo" (p. 50); de este modo, la intertextualidad entre el testimonio de Cai-

9 Esta décima ha sido grabada en varias ocasiones: 1) En un diálogo negroide a cargo de dos recitadores de La Cuadrilla Morena de Juan Criado, en el LP Festejo; por lo menos se alude a dos estrofas con ciertas alteraciones. 2) Como parte de un zapateo criollo en Con Victoria y Gente Morena; es recitada parcialmente, solo la primera y última estrofa, por Nicomedes Santa Cruz e intervienen los hermanos Abelardo y Oswaldo Vásquez, quienes modifican el verso por "desde Lima a Chancayllo". 3) En la canción "El negro Pepián”, interpretada por Arturo "Zambo" Cavero (1940-2009), como parte intermedia, en la que se conserva la glosa y la primera estrofa, modificada ligeramente en dos versos. 
tro Soto y el de Erasmo Muñoz (1895-1966) es de más evidente. ${ }^{10}$ 2) en los libros Décimas (1960) y Décimas y poemas. Antología (1971a) de Nicomedes Santa Cruz (1925-1992); la primera versión aparece en un español estándar, mientras que en la segunda edición de Décimas (1966) y posteriores publicaciones se intenta reproducir una variante lingüística cultural, el habla del negro costeño.

En cuanto a la segunda décima, Caitro Soto apenas cita la glosa, que es como sigue: "Anoche juegue y perdí, / lo mismo será mañana; / para jugar y perder, / machete, estate en tu vaina" (p. 50). He de anotar que Nicomedes Santa Cruz, en su libro La décima en el Perú (1982), incluye una décima completa con esta glosa, recitada por Carlos Vásquez Aparicio (1891-1954). Interesa detenerse en esta otra versión, a saber: "Anoche jugué y perdí, / y esta mañana a las siete, / para jugar y perder, / ¡Tate en tu vaina, machete!...” (p. 231). Esto es, partiendo de una glosa anónima, Vásquez Aparicio da origen a una nueva versión.

Como se sabe, la copla y la décima son expresiones poéticas itinerantes, es decir poseen una gran tradición y difusión tanto en la península Ibérica como en Latinoamérica. No ha de ser extraño que una misma glosa haya dado pie a la creación poética de una, dos o más décimas. O que se trate de una glosa con diversas versiones, que es lo que al parecer sucede en este caso en particular.

Así Vásquez procedente de Chancay y Soto de Cañete, coinciden en la capital. Esto dio paso al intercambio y el enriquecimiento cultural de ambos. Además, comparativamente la glosa en análisis, dos de cuatro versos se mantienen inalterados, el primero y el tercero; mientras que el segundo posee ligeras diferencias y el cuarto verso se ha cambiado el orden sintáctico.

En tercer lugar, el testimonio de Caitro Soto adquiere un tono distinto cuando se trata de la ciudad. Los hechos relatados se sitúan después de 1948. Es la etapa en el que "la vida era bien dura" (p. 47). Huérfano de padre, abandona la escuela y se incorpora a la vida laboral a los catorce años. Así realiza oficios diversos: contrabandista de carne, chofer de ómnibus, obrero de construcción civil, estibador en el puerto, aprendiz de boxeador, mecánico y vendedor de autos, taxista, etc.

Asimismo, es una etapa también de aprendizaje y perfeccionamiento: actúa; canta festejos, pregones, aguanieves; zapatea; toca la tumba, la guitarra y el cajón. Participa de la bohemia criolla en Barrios Altos y en el "Callejón del Buque" en La Victoria. Entre los dieciocho y veintidós años se dedica con más ahínco a su carrera profesional como artista, y progresivamente participa en "Pancho Fierro", "Gente Morena”, "Los Hermanos Soto", "Perú Negro”, e incluso logra con los años el prestigio internacional al lado de Chabuca Granda.

10 Esta décima ya ha sido motivo del análisis semiótico en un anterior trabajo. Ver Carazas (2011). 


\section{Memoria y música negra en el testimonio de Caitro Soto}

Antes de continuar me voy a detener en el tema de la memoria. La socióloga Elizabeth Jelin (2002, p. 18) ha planteado que existen cuatro ejes que es necesario considerar en el estudio de la memoria. El primero corresponde al sujeto que recuerda y olvida; el segundo está dado por el contenido del recuerdo y el olvido; el tercero está relacionado con el tiempo y el modo en que se recuerda; y, por último, el cuarto tiene que ver con el carácter expresivo o performativo. Esto nos lleva a reflexionar que el testimonio puede ser considerado como una "construcción de memorias" (p. 96). Entiéndase bien, abarca a su vez una multiplicidad de voces y también silencios.

Volviendo al testimonio de Caitro Soto, considero que él como representante de una colectividad expresa la riqueza del lenguaje popular de la costa y, sobre todo, es el depositario de la herencia cultural y musical del afroperuano. Estos dos aspectos son de suma importancia para entender el valor que adquiere este texto en particular. En los siguientes párrafos voy a dedicarme a desarrollar ambos tópicos.

El primer aspecto que llama la atención en el testimonio de Caitro Soto es la presencia de lo que él llama repetidamente "la música negra". En realidad, el informante alude a danzas y géneros musicales y literarios diversos. Ya antes he nombrado algunos, pero recién voy a referirme a ellos detenidamente en este apartado.

Pero ¿a qué nos referimos cuando decimos formas y géneros musicales y literarios afroperuanos con exactitud? Para responder esta pregunta será indispensable tomar en cuenta que la literatura afroperuana se caracteriza por ser heterogénea, sincrética y transcultural. Se manifiesta en dos sistemas: el escrito y el oral. El segundo sistema corresponde al de la tradición oral y musical y está caracterizado por lo festivo, lo irónico, lo popular y lo rítmico. Este corpus estaría conformado por los pregones, la cumanana, ${ }^{11}$ la décima, la saña, ${ }^{12}$ los cantos de cuna, etc.

Considerando el repertorio musical de Caitro Soto presente en su testimonio, se observa que en total son doce canciones, a saber: seis son de autoría o adaptaciones del autor (“A saca' camote con el pie” (landó), "Yo tengo dos papás” (festejo), “Curruñao" (festejo), "Canto a Cañete" (festejo), "Toro mata” (landó con fuga) y "Quema tú" (alcatraz)); una es una adaptación ("Negrito de Angola” (lamento)); otra

11 Es un género literario musical. Consta de cuartetas octosílabas en las que riman el segundo verso con el cuarto, quedan libres el primero y el tercero. Es difundido en Lambayeque, Piura y Tumbes. Uno de sus exponentes de mayor prestigio es Fernando Barranzuela de Yapatera-Piura, entre otros. La cumanana ha sido estudiada por Nicomedes Santa Cruz (1972a), Luis Rocca (1985 y 2010) y Carlos Espinoza León (2007).

12 Según Mejía Baca (1938c), fue un canto profano-religioso. Coincide en el nombre con el pueblo del norte, en Lambayeque, donde se sigue difundiendo. Es interpretada por solista y coro, acompañada tradicionalmente por el checo o calabazo. Consta de tres partes: la glosa, el dulce y la fuga. Una versión popular fue recogida por Nicomedes Santa Cruz en su disco Cumanana. El tema de la saña ha sido ampliamente estudiado por Luis Rocca (1985 y 2010). 
es una recopilación ("Una negra y un negro" (festejo)); tres corresponden a otros compositores e intérpretes ("Pobre negrito" de Lucila Campos, "Zamba malató" (landó) de Nicomedes Santa Cruz, "Krye y Gloria" (triste ${ }^{13}$ con fuga de tondero ${ }^{14}$ ) de Chabuca Granda); y una es un vals popular ("La andarita"). ${ }^{15}$

Para el profesor Robert Hodge (1999), la canción es un sistema de signos que representa un género específico, que más que individual pertenece a toda una cultura. Puede que su significado sea individual pero los códigos que transmiten son sociales. Es por esta razón que en este apartado voy a revisar el repertorio de Caitro Soto, en especial las canciones que se inscriben en los géneros festejo, alcatraz y landó.

Para empezar, el festejo es uno de los géneros musicales y dancísticos más representativo de la cultura afroperuana. Habría que considerar tanto el baile como la canción, cuya temática suele remitir a la esclavitud o al asunto erótico-festivo. Según Tompkins (2011, p. 123), en una comunicación personal, Augusto Áscuez (1892-1985) señala que la pareja realizaba movimientos de cintura para abajo durante el baile. Existe mucha controversia y opiniones contrarias sobre su origen. Por ejemplo, Nicomedes Santa Cruz (1964c) opina que la coreografía original del festejo se desconoce y que este nació en Lima hacia el siglo XVII.

En realidad, su repopularización en el siglo XX, se debe a Porfirio Vásquez (1902-1971) quien combinó pasos del Son de los diablos y la resbalosa, y le dio forma a la coreografía hacia 1949. Con el paso de los años se recuperaron algunos festejos como "Taita guaranguito", "Congorico", "Que se quema el sango", etc. El investigador William Tompkins (2011, p. 123-124) apunta que "el texto no sigue una forma poética pre-establecida. El esquema de las rimas y la estructura son variables. También se encuentra con frecuencia el verso libre [...] un festejo completo suele tener uno o más estribillos y algún tipo de coro que suele tomar la forma de una fuga”.

13 Según Mejía Baca (1938b), el triste es un producto híbrido, un canto amoroso y melancólico de la costa norte. Nicomedes Santa Cruz (1972b) considera al triste como un género folklórico eminentemente lírico-musical, cantado por hombres o mujeres. Posteriormente, gracias a la radio y la grabación comercial, en Lima, se ha acostumbrado a grabar el tondero precedido de un triste.

14 Es un baile de pareja del norte del país. Según Mejía Baca (1938a), es una forma de manifestación popular que desborda sensualismo y picardía. Nicomedes Santa Cruz propuso sin demostrarlo que se originaba en la saña y que a su vez del lundú angoleño. Tompkins (2011) explica que se trata de forma musical ternaria y consiste en la glosa o tonalidad menor, el dulce o canto en el relativo mayor y la fuga que cierra para regresar al menor original. Varios autores, entre ellos Chalena Vásquez (1996), coinciden en que es una expresión afromestiza. Para más información, revisar el libro de Quillama (1990).

15 "El canto a Luis Pardo" (La Andarita), según Nicomedes Santa Cruz (1982), es un poema compuesto en décimas, que apareció en el semanario La Integridad, fundado y dirigido por Abelardo Gamarra, en 1909. Más tarde, Juan Arredondo compuso la música en tiempo de vals y desde entonces se cantan las estrofas I, V, IX y XI, preferentemente. Ha reaparecido la versión completa en el libro Celajes, florestas y secretos. Una historia del vals popular limeño (2009), de José Antonio Lloréns y Rodrigo Chocano. La versión de Caitro Soto, pese a conservar las cuatro estrofas del vals, se canta con algunas alteraciones. 
En el caso de Caitro Soto se observa la inclusión de cuatro festejos, uno de ellos recopilado. Para este análisis, he elegido "Yo tengo dos papás". Este es un texto muy breve, cuenta apenas con tres estrofas que se van repitiendo. El informante explica que se trata de la historia de "una negra tramposa que tenía a su marido y tenía a su amante” (p. 75). Al llegar el esposo se calentaba la comida en el fogón mientras que el otro, el referido amante, se escondía en una canasta de caña tejida. Uno de los hijos repetía con razón un estribillo entre irónico y pícaro. Los hechos están situados, de acuerdo con la anécdota, en Cañete. Como se aprecia a continuación:

Yo tengo dos papas,

uno que 'tá en la canasta

y otro que 'tá en el fogón

Cuchuchu, cara de perro, (bis)

los frejoles que 'tán guardando

desde ayer

borico los va a comer

Y dijo

pan con sánguche,

lo mismo 'tá bueno...

Es curioso pero este relato, que es musicalizado, pertenece, en realidad, a la tradición oral afrocosteña. Así encontramos una versión más elaborada y con un final distinto en el "Ángel de la pichona", que aparece en Cuatro cuentos eróticos de Acarí (2004), de Gregorio Martínez (1942- ). El propio escritor, nacido en Coyungo muy próximo a Nazca, revela que las historias que contiene el libro fueron relatadas por familiares de Acarí, localidad ubicada más al sur, en la provincia de Arequipa.

Por un lado, el alcatraz ${ }^{16}$ es también una danza erótica-festiva que pertenece al género festejo. Como explica Chalena Vásquez (1996), "el hombre y la mujer llevan en la parte posterior de la cintura un pedazo de papel o algo parecido; el hombre con una vela encendida intenta prender el 'cucurucho' mientras la mujer baila, moviendo las caderas". Por tanto, tiene mucho de juego y erotismo. Según Caitro Soto, se trataría de "un baile de origen sexual" (p. 83).

La versión que alcanza el informante, "Quema tú", se remite al pasado de esclavitud y a un presente en el que este "ritmo" ha traspasado las barreras sociales y raciales, hoy es bailado por "blancos y negros" (p. 82). Lo cual es bastante aleccionador, ya que el baile de "los negros esclavos" ha sido asimilado por otras etnias. E1

16 Manuel Acosta Ojeda (2009c) sostiene que el nombre alude peyorativamente al movimiento de las caderas de la negra, lo que recuerda al ave marina. Existen dos canciones muy populares en nuestro medio, la de Caitro Soto y “Préndeme la vela” (1960) de Abelardo Vásquez (1929-2000). El alcatraz ha sido estudiado por Pinilla (1980), Tompkins (2011) y Velarde (2013). 
pasado queda representado como el tiempo de la distinción de jerarquías sociales y el trabajo forzado; en cambio, el presente queda signado ilusoriamente por la unión, a través de la música, ya que esta puede ser transgresora y democratizadora. Esto se puede apreciar en el siguiente texto:

Cuando los negros esclavos se ponían a bailar este ritmo muy sabroso que se llama el alcatraz

Quema tú, que no quemarás, quema el alcatraz

Qué dulzura en la cintura tiene la negra Pilar, qué lisura en la cadera pa' bailar el alcatraz

Quema tú, que no quemarás, quema el alcatraz

Este ritmo bien sabroso que todos bailamos ya lo bailan blancos y negros al compás del alcatraz

Quema tú, que no quemarás, quema el alcatraz

Por otro lado, el landón ${ }^{17}$ es un género bastante controversial, dado que los investigadores tienen opiniones diversas sobre su origen, etimología del vocablo e influencias posibles. Por ejemplo, Nicomedes Santa Cruz (1967) insiste en que es de herencia africana, pues su procedencia se derivaría de cierta danza llamada lundú. Lo cierto es que el primer landó que llega a ser popular en el siglo XX, "Zamba malató”, ${ }^{18}$ es grabado por N. Santa Cruz y su grupo Cumanana en 1964.

Para el etnomusicólogo Tompkins (2011: 146), quien compara varios landós, afirma que "la canción empieza con un preludio instrumental, y un interludio instrumental puede dividir algunas secciones. La forma melódica generalmente con-

17 Según Heidi Carolyn Feldman (2009), existen dos landós históricos: a) el de la familia Santa Cruz, y b) el de Perú Negro, tomado de Tompkins. La innovación es posterior y está a cargo de Chabuca Granda; el arreglo musical de la guitarra es de Félix Casaverde (1947-2011) y del cajón de Caitro Soto.

18 Según Octavio Santa Cruz (1996), la versión conservada gracias a la tradición familiar es reconstruida y cantada por el propio Nicomedes; la coreografía es de Victoria Santa Cruz (1922-2014) y el acompañamiento de guitarra es de Vicente Vásquez Díaz (1923- ). 
siste en dos o tres secciones organizadas en una forma estrófica general [...] El texto no se adhiere a ninguna forma poética en particular y las repeticiones del mismo siguen las de la melodía". Efectivamente, si atendemos a la letra, esta consta de un verso repetitivo: "sama malató, landó, sama malató", por lo menos en las versiones recogidas de Tompkins, la más antigua cantada por Augusto Áscuez en 1975. ${ }^{19}$

Una de las canciones populares de landó es "Toro mata", cuyas versiones han sido recopiladas en Cañete y en Chincha, principalmente. He ahí la contribución del mismo Caitro Soto quien hizo los arreglos y la cantó, para luego ser popularizada por el grupo Perú Negro. Veamos a continuación su versión:

Toro mata y... toro mata, toro mata, rumbambero, ay, toro mata

La color no le permite hace el quite a Pititi, ay, toro mata, toro, torito

Toro viejo se murió, mañana comemos caine, ay, toro mata

Toro mata y... toro mata, toro mata, rumbambero, ay, toro mata

Ay, Lapondé, pondé, pondé ay, Lapondé, é, é

Este negro no es de aquí, caracra, cra, cra, cra; este negro es de Acarí

caracra, cra, cra, cra

Hay que matar a este negro ¿quién trajo este negro aquí? caracra, cra, cra, cra

Ay, Lapondé, pondé, pondé ay, lapondé, é, é

(p. 80)

Para J. C. Cooper (2002), el toro se relaciona con el principio masculino de la naturaleza; es una criatura solar y representa la fuerza renaciente de la primavera.

19 Habría que agregar que el propio Augusto Áscuez, opina que el landó no existió como género; era apenas unos versos de un festejo. Ver Pimentel (1982b). 
Por tanto, es un símbolo de la virilidad y la fecundidad. Su bramido se identifica con el trueno, la lluvia y la fertilidad. Como es sabido, el toro es un animal que ha ingresado en el imaginario de la Humanidad y ha sido adorado como una divinidad tanto en Oriente (p. e.: Apis en el Antiguo Egipto) como en Occidente (v.g.: el Minotauro en Creta) desde tiempos remotos.

Ahora bien, la presencia del toro en el mundo andino ha sido investigada desde las ciencias sociales, el folklore y la crítica de arte. ${ }^{20}$ En cuanto a la imagen del toro en el contexto afroperuano, esta ha influenciado la literatura (como sucede con la obra de Manuel A. Segura, Ricardo Palma, Abelardo Gamarra, Gregorio Martínez y Lucía Charún-Illescas) y la pintura (principalmente, Francisco Fierro quien ha sabido retratar la presencia del negro en la corrida de toros en el s. XIX); sin embargo, aún no se han producido estudios críticos más serios. ${ }^{21}$

Respecto al "Toro-mata”, Fernando Romero (1988: 263-264) sugiere que esta danza-canción "sea una supervivencia tradicional afronegra" relacionada con "manifestaciones religiosas o folclóricas que proceden tanto de la región noroccidental como de la sudoccidental del África”. En cambio, Tompkins (2011) recopiló cinco versiones populares modernas del toro-mata ${ }^{22}$ y le dedica un capítulo completo de su tesis, pero considera que falta más información sobre el toro-mata tradicional original que se remonta al s. XIX.

Por otra parte, en el testimonio en análisis, Caitro Soto hace un comentario extenso respecto a esta relevante canción. Como antes, su origen está basado en la tradición oral familiar: "El 'Toro mata' viene de lo que me contaba mi abuela, mi bisabuela. La canción la armé y la hice yo con cosas que me narraban mis ancestros" (p. 81). Esta misma afirmación se repite varios años atrás cuando Tompkins (2011: 283) recoge de los hermanos Carlos y Orlando Soto una versión musical muy similar del Toro mata en la década del setenta.

Observando con detenimiento el contenido de la canción y el comentario personal del informante, propongo que la canción tiene hasta tres ejes temáticos. El primero está dado por la corrida de toros y la presencia de un torero de tez negra, a quien "la color no le permite hacer el quite" (p. 80), es decir, no lograba concluir

20 Ver Tomoeda (2013), entre otros.

21 Vale la penar recordar al destacado torero Ángel Valdez (1838-1911). Ver Gregorio Martínez (1982).

22 Las versiones del Toro-Mata corresponden a: 1) Manuel Quintana; 2) Carlos y Orlando Soto (Chancay); 3) Augusto Áscuez; 4) Bernardita Rivadeneira Rivera (San Vicente de Cañete); y 5) Francisco Farfán Gallardo-Jesús Cartagena y Víctor Peña Castillo (E1 Guayabo-Chincha). Es decir, estas fueron recopiladas, principalmente, en los departamentos de Lima e Ica en la década del setenta. 
su faena y era desvalorado frente a otros. Este fragmento nos remite a un pasado de discriminación y de tradición taurina. ${ }^{23}$

El segundo tema, en que aparece "Toro viejo se murió, mañana comemos caine” (p. 80), alude a la situación de extrema pobreza del negro, para quien estaba negada la carne de vacuno por su elevado costo, pero gracias a la corrida tiene la oportunidad casi celebratoria de darse un festín. Históricamente, desde la Colonia, las partes de la res que los españoles, y después los criollos, descartaban eran comestibles para otros, lo que implementó una cocina afroperuana creativa y deliciosa. ${ }^{24}$

El tercer tema está en relación con lo relatado por el informante sobre "un negro que se había venido de Acarí [...] Él no se había enterado de la libertad. Se había escondido entre las cañas comiendo fruta y lo que encontraba para alimentarse, y fue para el valle de Cañete. Y hambriento fue a Lapondé, y por la marca de su cuerpo se dieron cuenta que no era de allí" (p. 81). Esta historia puede que se remita al siglo XIX, cuando todavía se marcaba el cuerpo del esclavo con la carimba (o instrumento de hierro caliente). Curiosamente ha sido conservada de generación en generación, hasta llegar a la familia Soto; de ahí su apreciable valor histórico y cultural. El pasado traumático queda registrado por la memoria oral para luego mantenerse asombrosamente vigente a través del canto y la música.

Asimismo, Caitro Soto consigna en su repertorio la canción "A saca' camote con el pie" en ritmo de landó. ${ }^{25}$ No hay duda de que se emparenta con el festejo más antiguo que se conoce en el país, del cual se conserva el verso "Molino, molero, molino solo "standando". Este fue recopilado por José Durand de Bartola Sancho Dávila (1883-1977), sobrina de la ex esclava Juana Irujo de quien la aprendió. ${ }^{26}$

Ya hemos visto que el informante tiene como referente siempre la tradición familiar. La versión modernizada de Caitro Soto $^{27}$ es como sigue:

A sacá' camote con el pie, a sacá' camote con el pie

María del Carmen taba' buena, de repente hocico ya quemó;

$23 \mathrm{Al}$ parecer Caitro Soto altera la versión original y le agrega el nombre de Eusebio "Pititi" Sirio (1951-2001), ex cajonero y bailarín de Perú Negro. Ver Andrade (1997).

24 Se puede mencionar, a grosso modo, platos como el cau cau o mondongo, la chanfainita, los anticuchos, etc. Ver Rosario Olivas Weston (1996), (1998) y (1999).

25 Según Tompkins (2011), esta fue descubierta, en la zona de Chincha y Cañete, por Ronaldo Campos de la Colina (1927-2001), cajoneador, bailarín y ex director de Perú Negro.

26 Bartola Sancho Dávila fue una reconocida bailarina en las fiestas criollas de las Pampas de Amancaes. Ganó el concurso de baile de 1927, 1934 y 1939, por lo que es recordada como la "Reina de la Marinera". Ver Áscuez (1983).

27 Comparativamente, la versión cantada de Lucila Campos (1938- ) viene acompañada por un coro de voces e instrumentos como la guitarra, el cajón, la tumba, el bongó y la quijada. 
molino, molino, molinar

molino sólo ta' andando

A sacá' camote con el pie, a sacá' camote con el pie

Andá uté, negro Fraicico, que allá 'tá capitulero;

luego que empuña la plata

y el papelito afrojá'

irá uté' derechito

a otra parroquia a votá'

Quebranta boriquita

boriquita quebranta

Que remonio de borica, que no quiere caminá'

A sacá' camote con el pie, A sacá' camote con el pie

Esta canción está compuesta por una suma de hechos que ocurren a diferentes personajes, a manera de un collage. El referente aludido es la vida en el campo y el tiempo no es otro que el de la hacienda. Como explica Caitro Soto, "antes se molía a pulso la caña en el trapiche" (p. 71) y un buen día el molino se moderniza con un motor, por eso la canción expresa además la sorpresa del interlocutor porque el "molino solo 'tá andando" (p. 70).

La estrofa central más bien expresa la circunstancia de las elecciones en el que Fraicico $^{28}$ se le dificulta su votación y debe movilizarse a otro lugar. El estribillo recuerda que en otro tiempo se trabajaba descalzo la tierra y, por tanto, al prepararse el camote en la fogata se retiraba caliente con ayuda del pie. Al menos es lo que explica con detalle Caitro Soto, y lo mismo refirió el músico Orlando "Lalo" Izquierdo (1950- ) en una conversación personal.

El segundo aspecto que llama la atención en el testimonio de Caitro Soto es que algunas de sus canciones intentan reproducir el habla del afroperuano como, por ejemplo: "Pobre negrito" (p. 61), "Zamba malató" (p. 64), "A saca' camote con el pie” (p. 70), "Yo tengo dos papás” (p. 74), "Curruñao" (p. 76), "Canto a Cañete” (p. 78) y "Toro mata” (p. 80). Es decir, de doce canciones del repertorio musical, siete

28 Este es el nombre común que alude al negro como personaje en la literatura, como puede apreciarse en los cuentos de Nicomedes Santa Cruz, Antonio Gálvez Ronceros, Cronwell Jara y Gregorio Martínez. En la tradición oral y musical afroperuana es conocida la llamada de fuga: "Fraicico, bota frifró / que son comé veranique" o, mejor dicho, "Francisco, bota los frejoles que vamos a comer venado". 
presentan un registro que se vale del alfabeto ortográfico para representar los procesos fonéticos del habla de los pobladores de la etnia afroperuana. Asimismo, esto se percibe en algunos fragmentos de canciones que aparecen en el presente testimonio.

María del Carmen Cuba (1999, p. 25) explica que "la escritura fonética (a diferencia de la escritura normativa) puede reflejar de manera más fiel el habla de los pobladores". Cabe agregar que, según la lingüista, no hay características exclusivas de la etnia negra, pues estas se encuentran amalgamadas con otros rasgos del habla popular en general y del habla popular de la costa, así como rasgos de poblaciones indígenas en el aspecto fonético o léxico. Ya con anterioridad, Fernando Romero (1987) ha demostrado, con anterioridad, que el negro que llegó al Perú pasó por un proceso de transculturación lingüística, estuvo bajo la influencia de lenguas como el castellano, el quechua, entre otras.

En el análisis de estas canciones de Caitro Soto, es posible observar algunos fenómenos fonéticos, los que voy a reunir básicamente en tres grupos. En primer lugar, fenómenos del habla popular, en general, por ejemplo: a) que 'tá en la canasta (p. 74) 'está', molino solo 'ta andando (p. 70) 'estaba', lo mismo 'ta bueno (p. 74) 'está'; que 'tan guardando (p. 74) 'están'; b) pa' bailar el alcatraz (p. 82) 'para bailar', po' cochino (p. 76) 'por cochino'; lampa pa' trabaja (p. 78) 'para trabajar', una negra pa' vivir (p. 55) 'para vivir'.

En segundo lugar, fenómenos del habla popular de la costa que comparte la etnia negra, como por ejemplo: a) elisión de /s/ al final de la sílaba o de palabra, como: te comite a mi curruñao (p. 76) 'comiste', lo ha visto uté (p. 76) 'usted'; b) elisión de /r/ de la sílaba o de palabra, tal como: los negritos salen pronto a zapateá (p. 78) 'zapatear', agarran lampa pa trabajá (p. 78) 'trabajar', a sacá camote (p. 70) 'a sacar', a votá (p. 70) 'votar'; c) uso de /r/ por /1/, como: y el papelito afrojá (70) 'aflojar'.

En tercer lugar, fenómenos fonéticos exclusivos del habla de los negros y del grupo étnico cañetano, a saber: a) uso de /r/ por / $\mathrm{rr} /$, como en: quebranta boriquita (p. 70) 'borriquita', a otra paroquia (p. 70) 'parroquia'; b) elisión de /d/ en la última sílaba, delante de vocal y elisión silábica, como: que pronto se lo ba llevao (p. 76) 'llevado', irá uté derechito (p. 70) 'usted'; c) reforzamiento de vocal acentuada, tal como: mañana comemos caine (p. 80) 'carne', tu dedo goido (p. 76) 'gordo'; d) uso de /r/ por /d/ y viceversa, como: que remonio (p. 70) 'demonio'.

Me ha parecido necesario detenerme en este tema poco conocido en nuestro contexto. Salvo el encomiable estudio de Fernando Romero (1987), que explica la transculturación lingüística del negro africano en el continente americano y el lenguaje que desarrolló en la costa peruana, así como los trabajos de María del Carmen Cuba (1996) y (1999), sobre el habla del negro de la costa sur en Chincha; los estudios etnolingüísticos en el Perú no han demostrado mayor interés en este campo de investigación recientemente. Por lo tanto, hay un vacío que bien merece ser atendido en un futuro inmediato. 
Para terminar, la canción y la música afroperuanas han sido compuestas recurriendo a la tradición oral y popular de las diferentes comunidades, en un esfuerzo por recopilar, recuperar y mantener viva la memoria del pasado, tan doloroso como la esclavitud y la diáspora africana durante la Colonia o tan difícil en la hacienda algodonera o cañavelera en tiempos republicanos, así como la realidad de extrema pobreza y discriminación en época más contemporánea.

El profesor Hodge (1999, p. 163-164), afirma que la canción como "una forma multisemiótica, en la que la letra, la música y la interpretación tienen su propio significado potencial, con la posibilidad de transmitir contenidos ideológicos que normalmente tiene mayor importancia que el significado verbal aparente". Considero que la canción afroperuana es tanto la expresión de una cultura como de una ideología, una manera de pensar y percibir el mundo, y habría que agregar, que esta propicia la reafirmación de una identidad.

El filósofo y sociólogo Zygmunt Bauman (2010, p. 40) ha dicho que "la identidad se nos revela sólo como algo que hay que construir desde cero o elegir de ofertas de alternativas y luego luchar por ellas para protegerlas después con una lucha aún más encarnizada”. Creo que el testimonio afroperuano contribuye enorme y significativamente en la reafirmación de la identidad cultural, ya no solo de un individuo sino la de una colectividad. Ese es el aporte y el valor que revela la lectura del testimonio personal de Caitro Soto y, más, al oír sus canciones. Y si se trata de una lucha, en términos de Bauman, opino que su voz, testimonio y música se opone a aquellos que pretenden desvalorar lo afroperuano.

\section{Referencias}

\section{Fuentes Primarias}

Martínez, Gregorio. (2004). Cuatro cuentos eróticos de Acarí (de fuente oral). Lima: Fondo Editorial del Congreso del Perú.

Matos Mar, José (y) Carbajal, Jorge (Compiladores). (1974). Erasmo. Yanacón del valle de Chancay. Lima: Instituto de Estudios Peruanos.

Santa Cruz, Nicomedes. (1960). Décimas. Lima: Librería-Editorial Juan Mejía Baca.

- (1964a). Cumanana. Lima: Librería-Editorial Juan Mejía Baca.

- (1971a). Décimas y poemas. Antología. Lima: Campodónico Ediciones.

- (1971b). Ritmos negros del Perú. Buenos Aires: Editorial Losada.

Soto De La Molina, Carlos. (1995). De cajón Caitro Soto. El duende en la música afroperuana. Lima: Servicios Especiales de Edición S. A. del Grupo Empresa Editora El Comercio. 


\section{Fuentes Secundarias}

Acosta Ojeda, Manuel. (2009a). "El panalivio y el Sereno”. Suplemento Variedades de El Peruano 130 (13 de julio): 15.

- (2009b). “El zapateo criollo”. Suplemento Variedades de El Peruano 133 (10 de agosto), p. 15.

- (2009c). "El alcatraz". Suplemento Variedades de El Peruano 135 (24 de agosto): 15.

- (2009d). "Historia de la zamacueca (1)". Suplemento Variedades de El Peruano 139 (21 de setiembre), p. 15.

- (2009e). "Historia de la zamacueca (2)". Suplemento Variedades de El Peruano 140 (28 de setiembre), p. 11.

- (2009f). "Historia de la zamacueca (3)". Suplemento Variedades de El Peruano 141 (5 de octubre), p. 11.

- (2009g). "Historia de la zamacueca (4)". Suplemento Variedades de El Peruano 142 (12 de octubre), p. 11.

- (2009h). "Historia de la zamacueca (5)". Suplemento Variedades de El Peruano 143 (19 de octubre), p. 11.

Andrade, Mariano de. (1997). "Vida y Milagros de Eusebio 'Pititi' Sirio. El Señor del cajón”. Quehacer 110: 104-107.

Áscuez, Augusto. (1983). “Bartola: nunca te olvidaremos”. Suplemento VSD del diario La República (14 de enero), p. 15.

Carazas, Milagros. (2011). Estudios Afroperuanos. Ensayos sobre identidad y literatura afroperuanas. Lima: Centro de Desarrollo Étnico.

- (2013). "La tradición oral afroperuana como patrimonio cultural" en Presencia y persistencia. Paradigmas culturales de los afrodescendientes. Lima: Centro de Desarrollo Étnico, pp. 35-58.

- (2015). "Hacia el estudio del testimonio afroperuano". Insula Barataria 17: 99-130.

Chocano Paredes, Rodrigo. (2012). ¿Habrá jarana en el cielo? Tradición y cambio en la marinera limeña. Lima: Ministerio de Cultura.

Cuba, María del Carmen. (1996). El castellano hablado en Chincha. Lima: Escuela de Postgrado / Universidad Nacional Mayor de San Marcos.

- (1999). "Monólogo desde las tinieblas: lengua, literatura y cosmovisión de los negros en Chincha”. Escritura y pensamiento 3: 9-44.

Denegri, Marco Aurelio. (2009). Cajonística y vallejística. Lima: Editorial San Marcos.

Durand Allison, Guillermo. (19999. "Canto y danza. Cuatro expresiones de la costa peruana (Agua 'e nieve, ingá, cumananas y samba landó)”. Cuadernos Arguedianos 2: 25-38. 
Espinoza León, Carlos. (2007). "Cumanana creación literaria regional de Piura" en Africanos y Pueblos Originarios (Relaciones interculturales en el área andina). Lima: Museo Afroperuano de Zaña, pp. 199-228.

Feldman, Heidi Carolyn. (2009). Ritmos negros del Perú. Lima: Instituto de Estudios Peruanos - Instituto de Etnomusicología de la Pontificia Universidad Católica del Perú.

Lloréns Amico, José (y) Chocano Paredes, Rodrigo. (2009). Celajes, florestas y secretos. Una historia del vals popular limeño. Lima: Instituto Nacional de Cultura.

Martínez, Gregorio. (1982). “Ángel Custodio Valdez'. El torero brujo”. Suplemento VSD del diario La República (28 de mayo), pp. 12-13.

Mejía Baca, José. (1938a). “El tondero”. El Comercio (sábado, 1 de enero), p. 12.

- (1938b). "El triste". El Comercio (domingo, 23 de enero) p. 9.

- (1938c). "La saña”. El Comercio (domingo, 30 de enero) p. 11.

Olivas Weston, Rosario. (1996). La cocina en el virreinato del Perú. Lima: Universidad San Martín de Porres.

- (1998). "La cocina afroperuana". Bongó. Boletín del Movimiento Negro Francisco Congo 2, pp. 20-22.

- (1999). La cocina cotidiana y festiva de los limeños en el siglo XIX. Lima: Universidad San Martín de Porres.

Pimentel, Jorge. (1982a). "Yo soy Pancho Ballesteros". Suplemento VSD del diario La República (14 de mayo), pp. 10-11.

— (1982b). "Augusto Áscuez: Rey y Señor de la Jarana”. Suplemento VSD del diario La República (21 de mayo), pp. 12-13.

Quillama Polo, Elena (Editora). (1990). El tondero como expresión folklórica y artística del Perú. Lima: Lluvia Editores.

Rocca Torres, Luis. (1985). La otra historia (Memoria colectiva y canto del pueblo de Zaña). Lima: Instituto de Apoyo Agrario.

- (2010). Herencia de esclavos en el norte del Perú. (Cantares, danzas y música). Lima: Centro de Desarrollo Étnico.

Rocca Torres, Luis; Figueroa, Evely (y) Arteaga, Sonia. (2012). Instrumentos musicales de la diáspora africana y museología. La experiencia del Museo Afroperuano de Zaña. Lima: Museo Afroperuano de Zaña.

Romero, Fernando. (1939). “Cómo era la zamacueca zamba”. Turismo 146: [10] - [11].

- (1987). El negro en el Perú y su transculturación lingüistica. Lima: Editorial Milla Batres.

- (1988). Quimba, Fa, Malambo, Neque. Afronegrismos en el Perú. Lima: Instituto de Estudios Peruanos. 
Santa Cruz, Nicomedes. (1964b). "El panalivio". Estampa. Revista de Expreso (23 de febrero) p. VII.

- (1964c). "El festejo". Estampa. Revista de Expreso (26 de enero), p. 7.

- (1967). "Lundu. Abuela africana de la marinera". Estampa. Revista de Expreso (5 de noviembre): 13 .

- (1972a). “Las cumananas”. La Nueva Crónica (domingo, 19 de marzo), p. 21.

- (1972b). "El triste y las versadas". La Nueva Crónica (domingo, 12 de marzo), p. 21.

- (1982). La Décima en el Perú. Lima: Instituto de Estudios Peruanos.

Santa Cruz, Octavio. (1996). "Hacia un nuevo folklore afroperuano". Imaginario del arte 12, pp. 54-57.

Santa Cruz, Rafael. (2006). El cajón afroperuano (2004). Lima: R Santacruz Ediciones.

Santa Cruz, Victoria. (1974). "Vientos, cuerdas y cueros de todo el Perú". Mundial 2 (del 20 al 27 de diciembre): [48] - 55.

Tompkins, William D. (2011). Las tradiciones musicales de los negros de la costa del Perú. Lima: Centro de Música y Danza de la Pontificia Universidad Católica del Perú - Centro Universitario de Folklore de la Universidad Nacional Mayor de San Marcos.

Vallejos Paulett, Francisco. (2012). Método de cajón peruano. Lima: Editorial Edigraber.

Vázquez Rodríguez, Rosa Elena. (1982). La vida musical de la población negra de Chincha. La Danza de Negritos. La Habana: Casa de las Américas.

- (1996). “Canto y baile negros en la costa del Perú”. Ideele 87, pp. 65-88.

Velarde Reyes, Carlos. (2013). "El juicio social, o tratar de ver el alcatraz desde una perspectiva estructural y dialéctica" en Presencia y persistencia. Paradigmas culturales de los afrodescendientes. (pp. 91-104). Lima: Centro de Desarrollo Étnico.

Zanutelli Rosas, Manuel. (1999). Canción criolla. Memoria de lo nuestro. Lima: Editora La Gaceta - Diario El Sol.

\section{Fuentes Complementarias}

Bauman, Zygmunt. (2010). Identidad. Buenos Aires: Losada.

Cooper, J. C. (2002). Diccionario de símbolos. Barcelona: Ediciones Gustavo Gili.

Cornejo Polar, Antonio. (1996). "Una heterogeneidad no dialéctica: sujeto y discurso migrantes en el Perú moderno”. Revista Iberoamericana 176-177, pp. 837844.

Hall, Stuart. (2010). Sin garantías. Trayectorias y problemáticas en estudios culturales. Lima: Envión Editores - Instituto de Estudios Sociales y Culturales - Universidad Andina Simón Bolívar - Instituto de Estudios Peruanos. 
Hodge, Robert. (1999). "Canción" en Discurso y literatura. Nuevos planteamientos sobre el análisis de los géneros literarios. VAN DIJK, Teun (Editor). Madrid: Visor, pp. [149] - 166.

Jelin, Elizabeth. (2002). Los trabajos de la memoria. Madrid: Siglo XXI - Social Science Research Council.

Parret, Hermann. (2008). Epifanías de la presencia. Ensayos semio-estéticos. Lima: Fondo Editorial de la Universidad de Lima.

Pinilla, Enrique. (1980). "Informe sobre la música en el Perú”. Historia del Perú. Proceso e instituciones. Tomo IX, pp. [361] - 677. Lima: Editorial Juan Mejía Baca.

Tomoeda, Hiroyasu. (2013). El toro y el cóndor. Lima: Fondo Editorial del Congreso del Perú.

\section{Discografía / CD}

Campos, Lucila. (2011). Gran colección de la música criolla. Lucila Campos. 11y6 Discos. 4 Discos Compactos.

Cavero, Arturo. (2011). Gran colección de la música criolla. Zambo Cavero. 11y6 Discos. 4 Discos Compactos.

Perú Negro. (2007). Zamba Malató. SBMC - Times Square Records. Disco Compacto.

- (2010). Perú negro. Sus raíces. Xendra Music. Disco Compacto.

Santa Cruz, Nicomedes. (2001). Socabón. Xendra Music. Disco Compacto

- (2010). Cumanana. Xendra Music. Disco Compacto.

Santa Cruz, Victoria. (2000). Con Victoria Santa Cruz y Gente Morena. Producciones Iempsa. Disco Compacto.

(2003). Ritmos y aires afroperuanos. Producciones Iempsa. Disco Compacto.

Soto De La Colina, Carlos "Caitro". (1995). De cajón Caitro Soto. Musical Group Peru. Disco Compacto.

(2008). El cajón es peruano... lo digo yo. Xendra Music. Disco Compacto. 